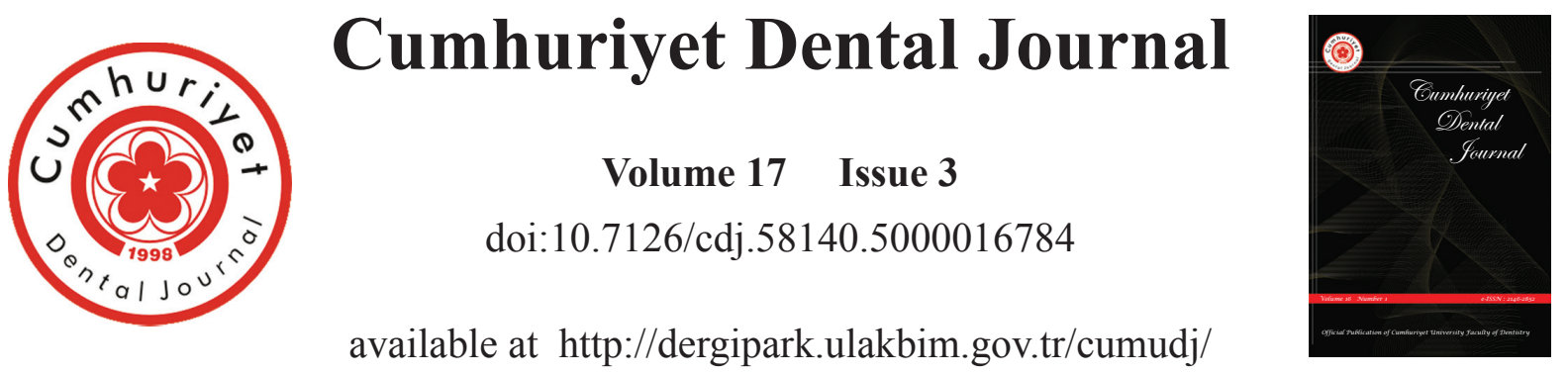

RESEARCH ARTICLE

\title{
The effects of disinfectant solutions on the viscoelastic properties of acrylic resins
}

\author{
Perihan Oyar, DDS, PhD, ${ }^{a}$ Gulsen Can, DDS, $P h D^{b}$ \\ ${ }^{a}$ Dental Prosthetics Technology, School of Health Service, Hacettepe University, Ankara, Turkey \\ ${ }^{b}$ Department of Prosthodontics, Faculty of Dentistry, Ankara University, Ankara, Turkey
}

\section{A R T I C L E I N F O}

\section{Article history:}

Received 09 May 2014

Accepted 25 June 2014

\section{Keywords:}

Acrylic resins

Disinfectant solutions

Dynamic mechanical thermal analysis

Viscoelastic properties

\begin{abstract}
A B S T R A C T
Objectives: The aim of this paper was to analysis the effects of disinfectant solutions on polyoxymethylene viscoelastic properties in comparison with polymethyl methacrylate.

Materials and Methods: Polymethyl methacrylate and polyoxymethylene acrylic and $200 \mathrm{~mL}$ $5 \%$ chlorhexidine gluconate, $2 \%$ sodium hypochlorite and one Corega Tabs dissolved in $200 \mathrm{~mL}$ water at $40^{\circ} \mathrm{C}$ were used. The storage modulus, loss modulus, Tan $\delta$ and glass transition temperatures of the disinfected acrylic resins were observed with the Thermal Dynamic Mechanical Analyzer.

Results: Lower storage modulus values were observed in the disinfectant solutions at polymethyl methacrylate specimens. The storage modulus showed lower values than the control group at chlorhexidine gluconate, higher values at sodium hypochlorite in the disinfectant solutions at polyoxymethylene specimens. While the glass transition temperatures of polymethyl methacrylate in the disinfectant solutions showed proximal values, the glass transition temperatures of polyoxymethylene in the chlorhexidine gluconate showed lower temperatures (approximately 11\%).

Conclusions: The storage modulus, loss modulus, Tan $\delta$ values of polyoxymethylene were lower than those of Polymethyl methacrylate. The Corega Tabs did not affect the viscoelastic properties of polyoxymethylene. Chlorhexidine gluconate and sodium hypochlorite did not affect the viscoelastic properties of polymethyl methacrylate.
\end{abstract}

\section{INTRODUCTION}

Ethylene-derived thermoplastic acetal resins have recently come into use as alternatives to metal substructures for removable partial dentures. These resins are a type of polyoxymethylene (POM) that have a branchless, linear chain structure formed by the polymerization of formaldehyde originating from free acetal resin monomers. Acetal resinisa polycrystallinestructureandan injection-molded resin. ${ }^{2}$ Acetal resin has been shown to have good physical and mechanical properties. The material has been also shown to have good biocompatibility that's why it was considered as a framework material for removable partial dentures for patients

Corresponding author at: Peihan OYAR, Dental Prosthetics Technology, School of Health Service, Hacettepe University, 06100 Sihhiye, Ankara, Turkey. Tel.: +90-312-305 15 87/111, Fax.: +90-312-3102730. E-mail: poyar73@gmail.com 
with allergic reactions to metal alloys. These properties make it an appropriate material for removable partial dentures, complete dentures, provisional bridges, occlusal splints, orthodontic and sleep apnea appliances. ${ }^{3-6}$ Prolonged use requires that these materials exhibit chemical and mechanical resistance in their surrounding environments over time. Numerous factors affect the mechanical properties of resins, including polymer molecular weight; ratio of residual monomers, plasticizers and cross-linking agents; internal porosity of the polymer matrix; material thickness; finishing techniques; contact with chemical agents; and patient-related factors. Resin properties may also be affected by loss of soluble components or water sorption, tension and temperature changes related to hot and cold food intake during clinical use. $^{7-10}$

The porous structure of acrylic resin as well as the presence of any surface scratches or pits allow microorganisms to easily attach themselves to an acrylicresin denture. Thus, in addition to longterm contact with oral tissue, saliva, blood and water in the oral environment, an acrylic-resin denture also requires immersion in a cleaning solution for long periods of time. Disinfection is necessary in order to minimize cross-contamination between the patient, dental personnel and the denture. ${ }^{11-13}$ McCabe et al. ${ }^{14}$ stress the need for proper disinfection of all prostheses. This may be achieved using various chemicals, including glutaraldehyde, chlorhexidine gluconate, alkaline peroxides, alkaline hypochlorites, diluted acids and enzymes. ${ }^{15}$ In addition, Gronitskey et al. ${ }^{16}$ have suggested that sodium perborate products (Corega Tabs) may have an antimicrobial effect.

The disinfection process is expected to have no negative effect on denture materials; however, a number of studies have reported some disinfectant solutions to cause undesirable changes in the physical properties of the acrylic base. ${ }^{17-19}$ Depending on the type and length of contact, disinfection agents may cause structural changes in the inner matrix of the polymer. ${ }^{20,21}$ Chau et al. $^{22}$ reported that $1 \%$ sodium hypochlorite eliminated microorganisms from the denture, and another study found immersion in $1 \%$ sodium hypochlorite, $4 \%$ chlorhexidine gluconate, or $3.78 \%$ sodium perborate for 10 minutes produced no change in the transverse strength of heat-polymerized polymethyl methacrylate. Similarly, Angelillo et al. ${ }^{23}$ stated that glutaraldehydebased disinfectants provided effective disinfection without causing degradation in plastic and rubber materials. Ayaz et al. $^{24}$ al stated that the effervescent denture cleaners (sodium perborate, sodium bicarbonate) may be degradation in polymer structure of acrylic resins and change color of acrylic resin teeth.

In contrast, other studies have reported changes in the flexural strength of resin immersed in sodium hypochlorite and, with heat application, alkaline peroxide. ${ }^{17,25}$ Shenet et al. $^{20}$ reported softening of resin surfaces exposed to glutaraldehyde alkaline disinfection with phenolic buffer for 2 hours, with the affect increasing with further exposure, and Peracini et al. ${ }^{18}$ found that Corega Tabs caused a considerable reduction in the flexural strength of acrylic resin as well as a color change.

DMA is a method used to analyze the viscoelastic properties of polymeric materials through the application and measurement of controlled sinusoidal stress. ${ }^{26-29}$ The null hypothesis was that different disinfectant solutions would affect the viscoelastic properties of POM and polymethyl methacrylate acrylic resin (PMMA). In order to better understand the effects of hygienic procedures on the viscoelastic properties of acrylic resin prosthetics, this study analyzed and compared the effects of 3 different 
disinfectant solutions on the viscoelastic properties of POM and PMMA acrylic resin using DMA.

\section{MATERIALS AND METHODS}

Two different types of acrylic resin [PMMA(QC-20 resin; De trey, Dentsplay, England) and POM (Dental D; Quatrotti, RovelloPoro, Italy)] and 3 different types of disinfectants [5\% chlorhexidine gluconate (Dental D, Quatrotti, RovelloPoro, Italy); $2 \%$ sodium hypochlorite (Miyako do Brazil Id e Com; Guarrulhos, Brazil); CoregaTabs (Stafford Miller; Dungarvan Co, Waterford, Ireland)] were used in this study.

Acrylic specimens $(20 \mathrm{~mm} \times 10 \mathrm{~mm}$ $\times 4 \mathrm{~mm}$ ) were prepared according to the manufacturers' instructions and divided into the following groups:

$\mathrm{Aa}(\mathrm{n}=1) \quad$ : PMMA/chlorhexidine gluconate $\mathrm{Ab}(\mathrm{n}=1) \quad$ : PMMA/sodium hypochlorite

Ac $(\mathrm{n}=1) \quad: \mathrm{PMMA} /$ Corega Tabs

$\mathrm{Ba}(\mathrm{n}=1) \quad: \mathrm{POM} /$ chlorhexidine gluconate

$\mathrm{Bb}(\mathrm{n}=1) \quad: \mathrm{POM} /$ sodium hypochlorite

$\mathrm{Bc}(\mathrm{n}=1) \quad: \mathrm{POM} /$ Corega Tabs

Ad ( $\mathrm{n}=1) \quad$ : PMMA/200 $\mathrm{mL}$ distilled water (control)

$\mathrm{Bd}(\mathrm{n}=1) \quad: \mathrm{POM} / 200 \mathrm{~mL}$ distilled water (control)

Disinfectants were dissolved in $200 \mathrm{~mL}$ distilled water at $40^{\circ} \mathrm{C}$ and thermocycled (MSCT-3 plus; Marcelo Nucci-ME, Sao Carlos, Brazil) at $5^{\circ}-55^{\circ} \mathrm{C}$ with a 60 -second dwell time. Each specimen was immersed for 10 minutes in one of the solutions, removed and rinsed for 2 minutes in distilled water. This procedure was repeated 30 times (to simulate approximately 6 months of denture usage).

A Thermal Dynamic Mechanical Analyzer (Perkin Elmer Pyris Diamond DMA; Model $983 \mathrm{MA}$ ) was used to measure the storage modulus (E'), loss modulus (E'), Tan $\delta$ and glass transition temperatures (Tg) of disinfected acrylic resin samples at
$\mathrm{N}_{2}$ atmosphere and temperatures ranging from -60 to $+250^{\circ} \mathrm{C}$ with heating rate of $10^{\circ} \mathrm{C} / \mathrm{min}$. (POM specimens could not be observed above $+160^{\circ} \mathrm{C}$ because of the melting point of the material).

DMA measurements are sensitive to micro-level structural changes and are capable of thoroughly analysing the viscoelastic behaviour of polymers with relatively few samples. Because of the small number of samples in the present study, a detailed statistical analysis was not performed. Similar recent studies of the viscoelastic properties of dental materials have also been conducted without performing statistical analysis. ${ }^{30-34}$

\section{RESULTS}

E' values are shown in Figure 1-3. Among PMMA specimens, E' values of specimens immersed in chlorhexidine gluconate $(\mathrm{Aa})$ (Fig. 1) were similar to those of the control group (Ad), whereas E' values of specimens immersed in sodium hypochlorite $(\mathrm{Ab})$ (Fig. 2) and in Corega Tabs (Ac) (Fig. 3) were lower than those of the control group. Among POM specimens, E' values of specimens immersed in chlorhexidine gluconate $(\mathrm{Ba})$ (Fig. 1) were lower than those of the control group (Bd), whereas E' values of specimens immersed in sodium hypochlorite $(\mathrm{Bb})$ (Fig. 2) were higher than those of the control group and E' values of specimens immersed in Corega Tabs (Bc)(Fig. 3) were similar to those of the control group.z

E" values are shown in Figure 4-6. Instances of decreases in E' values appear as peaks in E" values, with the first peak $(\beta)$ in $\mathrm{E}^{\prime \prime}$ values observed between $+5^{\circ}$ to $+24^{\circ} \mathrm{C}$ and the second peak $(\alpha)$ between $120^{\circ}$ to $125^{\circ} \mathrm{C}$ for PMMA, whereas POM peaks were observed between $-10^{\circ}$ to $-20^{\circ} \mathrm{C}(\beta)$ and peak between $115^{\circ}$ to $127^{\circ} \mathrm{C}(\alpha)$.

Tano (E'/E') values are shown in Figure 7-9. PMMA Tan $\delta$ values peaked at 
approximately $120^{\circ} \mathrm{C}$, whereas no marked peak was observed for POM. PMMA Tan $\delta$ values were similar for all disinfectant solutions and were lower than those of the control group. PMMA Tg temperatures were similar for all disinfectant solutions.

However, POM Tg temperatures were lower for chlorhexidine gluconate than for the other disinfectant solutions (Table I).

\section{DISCUSSION}

As a result of eating and drinking, acrylic resins are exposed to temperature change

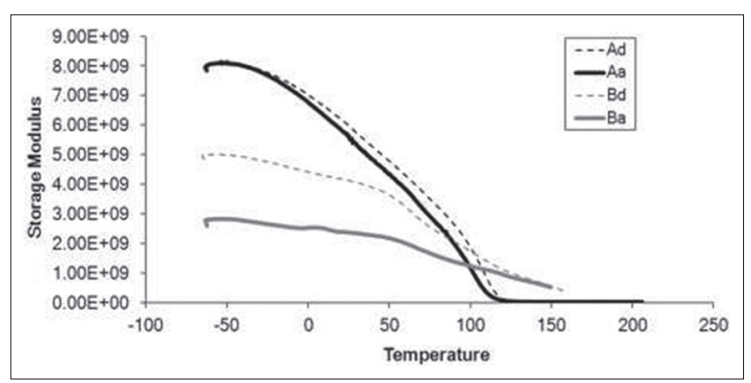

Figure 1. E' values of disinfectant solutions for chlorhexidine gluconate.

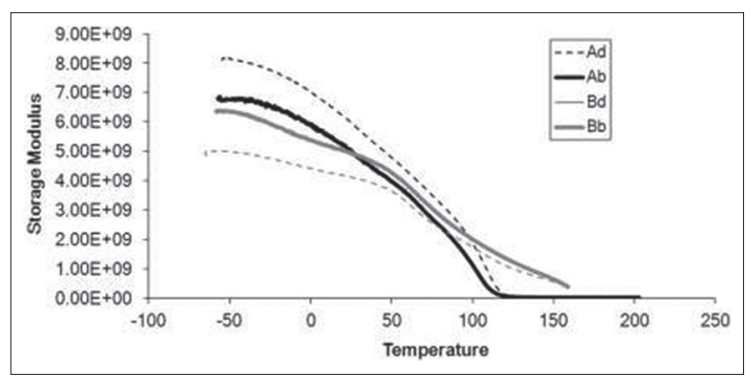

Figure 2. E' values of disinfectant solutions for sodium hypochlorite.

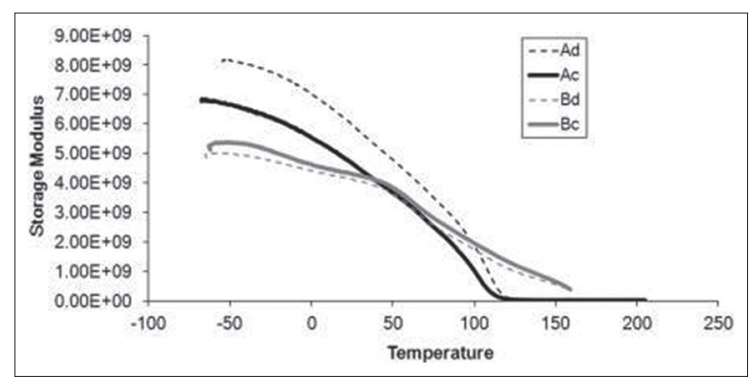

Figure 3. E' values of disinfectant solutions for Corega Tabs. and periodic stresses on a daily basis. Depending upon its duration, stress can produce a temperature change in the resin, and as the temperature increases, the polymers may be transformed into a viscous structure. If the cross-linking occurring as a result of polymerization is incomplete, the release of side groups of polymer chains may be observed in the DMA spectrum. ${ }^{27}$ The E' value determines its rigidity and depends upon its ability to store mechanical energy, while the E" value is associated with the energy absorbed during dynamic deformation. Tan $\delta$, that is, the

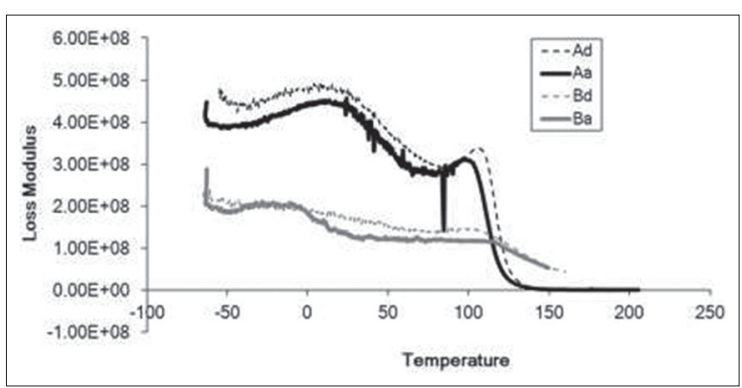

Figure 4. E" values of disinfectant solutions for chlorhexidine gluconate.

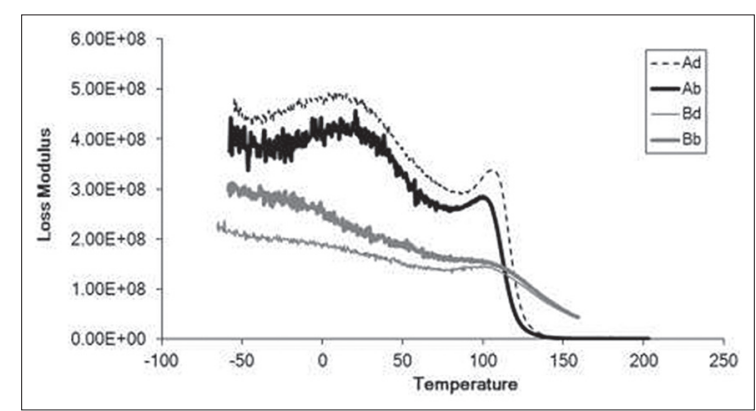

Figure 5. E" values of disinfectant solutions for sodium hypochlorite.

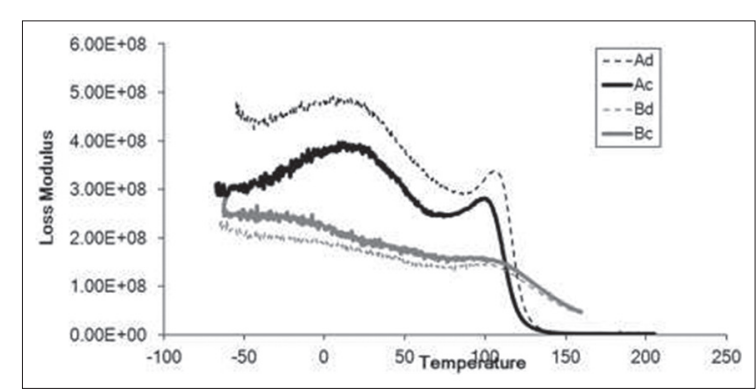

Figure 6. E" values of disinfectant solutions for Corega Tabs. 
Table 1. Glass transition temperatures (Tg) observed in the DMA spectrums.

\begin{tabular}{|l|l|l|l|l|l|l|l|l|}
\hline Polymer groups & $\mathrm{Aa}$ & $\mathrm{Ab}$ & $\mathrm{Ac}$ & $\mathrm{Ad}$ & $\mathrm{Ba}$ & $\mathrm{Bb}$ & $\mathrm{Bc}$ & $\mathrm{Bd}$ \\
\hline $\mathrm{Tg}\left({ }^{\circ} \mathrm{C}\right)$ & 120.78 & 121.52 & 121.27 & 125.46 & 114.98 & 124.85 & 122.99 & 127.05 \\
\hline
\end{tabular}

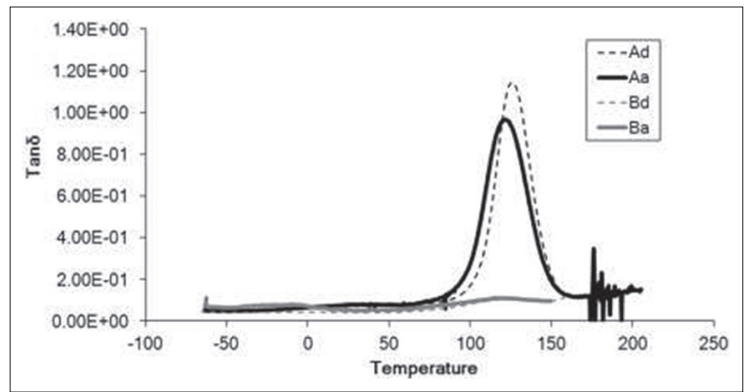

Figure 7. Tan $\delta$ values of disinfectant solutions for chlorhexidine gluconate.

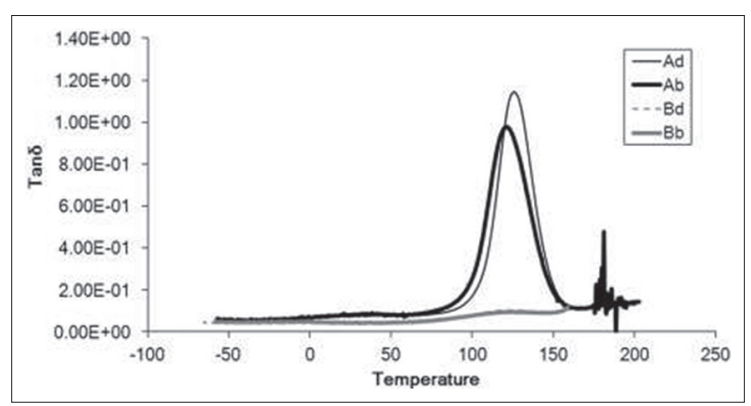

Figure 8. Tan $\delta$ values of disinfectant solutions for sodium hypochlorite.

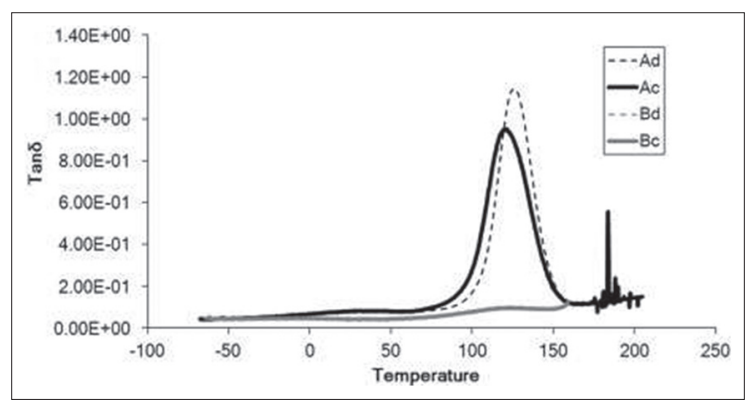

Figure 9. Tan $\delta$ values of disinfectant solutions for Corega Tabs.

ratio between E'/E', and the temperature at which polymer chains acquire the ability to move freely within a polymetric mass, represents the temperature at which the resin is transformed from a fragile glass with limited mobility to a totally fluid system..$^{32}$ Tan $\delta$ also provides an indication of the relative contribution of the elastic and inelastic components to the overall behaviour of the material. ${ }^{29} \mathrm{~A}$ high $\tan \delta$ indicates high molecular mobility, while a low $\tan \delta$ indicates less mobility in the material. As temperature increases, the $\tan \delta$ value and molecular mobility increases and the material approaches the rubbery. ${ }^{35} \mathrm{Tan} \delta$ corresponds to $\mathrm{Tg}$, a physical transformation in which a viscous or elastic material becomes a fragile glass. The midpoint of this transformation (the glass transition temperature) determines the temperature interval within which the material is suitable for use, with significant chain movements within the acrylic resin still occurring at the upper threshold of this interval. The Tg value of a polymer provides an indication of its cross-linking density. ${ }^{26}$ and depends mainly upon the flexibility of the main chain. Other factors affecting Tg include the affinity between molecules, the addition of plasticizers or monomers with a different $\mathrm{Tg}$, molecular weight, the amount of residual monomer and the density of polymerization. Moreover, any absorbed water acts like a plasticizer, affecting the affinities between the molecules, thereby lowering the $\mathrm{Tg}$ value and thus affecting the mechanical properties of the polymer. ${ }^{33,34}$ Orsiet et $\mathrm{al}^{8}{ }^{8}$ state that heating of the polymer resin that occurs during the polishing process creates a surface film that reduces water sorption, with residual monomers remaining within the internal porosities of the resin matrix. This residual monomer act as a plasticizer, adversely affecting the resin's mechanical properties and making it highly susceptible to deformation when subjected to stress. ${ }^{7,9}$ Hamanaka et $\mathrm{al}^{36}$ investigated the influence of water sorption on certain mechanical properties 
of injection-molded thermoplastic denture base resins. They reported that the water sorption significantly decreased the flexural strength and elastic modulus.

The main peaks in E" and the $\tan \delta$ curves show $\alpha$ relaxation in the main polymer chain. The peaks in the E" curve at low temperatures indicate $\gamma$ and $\beta$ relaxation within the side groups and/or chain segments. $^{28}$ A relatively low tan $\delta$ value indicates low molecular mobility and high elasticity, whereas higher tan $\delta$ values indicates greater molecular mobility as well as viscosity. ${ }^{37}$ In this study, the lower $\tan \delta$ values (approximately 9 times in +70 to $+160^{\circ} \mathrm{C}$ ) observed for POM in comparison to PMMA. Thus, this study indicates POM to be an acrylic with greater elasticity.

PMMA specimens immersed in $5 \%$ chlorhexidine gluconate, $2 \%$ sodium hypochlorite and Corega Tabs exhibited similar $\mathrm{Tg}$ values, all of which were lower (approximately 3\%) when compared to the control group. These similar $\mathrm{Tg}$ values indicate that crosslinking of the material inhibits the mobility of side groups, so that only the main chain exhibits movement in response to an increase in temperature. Moreover, the $\beta$ transitions observed in the spectrums indicate a free release in molecules from the polymer chains, whereas $\alpha$ transitions are indications of cross linking in the material and mobility in the main chain but no release of molecules. ${ }^{37}$ The use of 5\% Chlorhexidine gluconate led to lower $\mathrm{Tg}$ (approximately 11\%) in the POM. The use of $2 \%$ sodium hypochlorite and Corega Tabs led to lower $\mathrm{Tg}$ (approximately 3-4\%) in the POM.

Cross-linked polymers have lower flexibility and higher $\mathrm{Tg}$ values than non-cross-linked polymer resins. ${ }^{33}$ The differences found between PMMA and POM Tg values may be due to the fact that PMMA has a cross-linked structure, whereas POM is comprised of linear, branchless chains.
According to Ruyter et $a l .^{38}$ long distances between methacrylate groups contribute to more complete polymerization because of the high reactivity of the secondary methacrylate groups, which can be expected to contribute to a high degree of conversion and thus an increase in Tg. A decrease in the storage modulus value is an indication of an increase in flexibility. ${ }^{39}$ While PMMA E' and E" values showed no changes in 5\% chlorhexidine gluconate, when PMMA was immersed in sodium hypochlorite and a Corega Tabs solution, both these values decreased, indicating a slight increase in resin flexibility. Previous studies have shown $1 \%$ sodium hypochlorite and $4 \%$ chlorhexidine gluconate to have no negative effects on the flexural strength or hardness of acrylic resin, ${ }^{7,11}$ whereas CoregaTabs have been found to significantly reduce the flexural strength of acrylic resin..$^{18}$ Asad et al., ${ }^{17}$ however, found that immersion in $0.5 \%$ chlorhexidine gluconate for seven days did not result in any significant changes in the flexural strength of acryclic resins, but did lead to changes in surface hardness, whereas the flexural strength of non-crosslinked homopolymer resin specimens was significantly affected by immersion in alcohol-based disinfectants when compared to distilled water.

Peutzfeldt et $a l .{ }^{40}$ observed changes in acrylic surfaces as a result of contact with chlorhexidine digluconate and sodium hypochlorite, but not sodium perborate. The present study reported no changes in POM E' or E' values with Corega Tabs, but found that POM E' values decreased with chlorhexidine gluconate, indicating an increase in flexibility, and that both E' and E" values increased with sodium hypochlorite, indicating an increase in rigidity. Neppelenbroke et al. ${ }^{15}$ stated that $4 \%$ chlorhexidine gluconate, $1 \%$ sodium hypochlorite and $3.78 \%$ sodium perborate all led to significant decreases in the hardness of acrylic resin; however, this 
effect was reversed following immersion in water for 15 days.

Pisani et al. investigated effect of cleaner solutions for denture cleaning on the properties of acrylic resin teeth. They found that $1 \%$ sodium hypochlorite caused alterations on the hardness, rougness and color of acrylic resin teeth. ${ }^{41}$ Paranhos et al. reported that the alkaline peroxide and alkaline hypochlorite did not alter the flexural strength and $1 \%$ sodium hypochlorite solution caused increase in surface rougness of acrylic resin. ${ }^{42}$ Campanha et al. evaluated the effect of long-term disinfection procedures on the hardness of acrylic resin denture teeth. 4\% Chlorhexidine gluconate and $1 \%$ sodium hypochlorite and microwave sterilization decrease the hardness of the resin teeth. ${ }^{43}$ Pisani et al. evaluated colour stability, hardness and rougness of acrylic soft denture liners after immersion in denture cleaners. They found that $1 \%$ sodium hypochlorite caused on increase in roughness. ${ }^{44}$ Polyzois et al. ${ }^{3}$ investigated the effect of peroxide and hypochlorite cleansers on gloss, colour and sorption of acetal denture resins. The immersion of acetal resin in $\mathrm{NaOCl} 5.25 \%$ showed clinically unacceptable and higher sorption and should be avoided or should be managed with care. Alaa Al-Haddad et al. ${ }^{45}$ showned that Chlorhexidine reduced fracture toughness of the acrylic base (PMMA).

In this study, the E' values of PMMA specimens were higher (approximately 0.5 to 5 times) than those of POM specimens and PMMA specimen immersed in 5\% chlorhexidine gluconate had the highest E' values (approximately 5 times). Thus, this result indicates that PMMA was more rigid acrylic than POM. The E" values of PMMA specimens were higher (approximately 1.5 to 2.5 times) than those of POM specimens. The highest E" values was observed in PMMA specimen immersed in
$5 \%$ chlorhexidine gluconate.

The present study found slight differences in PMMA tan $\delta$ values observed among disinfectant solutions. These differences may be due to variations in the rate at which these solutions impact upon the resin surface film and thus differences in amounts of water absorption.

The null hypothesis was accepted because chlorhexidine gluconate and sodium hypochlorite affected the viscoelastic properties of POM, and Corega Tabs affected the viscoelastic properties of PMMA. The results of this study indicate that neither chlorhexidine gluconate nor sodium hypochlorite are suitable for cleaning POM prosthetics, whereas Corega Tabs should not be used to clean PMMA prosthetics.

The current study is limited in that only 2 type of acrylic resin and 3 type of disinfectant solutions are investigated. In order to identify the factors leading to changes in the Tan $\delta$ and Tg values of PMMA and POM, future studies should investigate factors such as polymer structure, crosslink density, water sorption and residual monomers.

\section{CONCLUSIONS}

Within the limitations of this study, the following conclusions were drawn:

1. E' (approximately 0.5 to 5 times), E" (approximately 1.5 to 2.5 times) and tan $\delta$ (approximately 9 times) values of POM are lower than those of PMMA.

2. The use of Corega Tabs, 5\% Chlorhexidine gluconate, $2 \%$ sodium hypochlorite disinfectant solutions led to lower $\mathrm{Tg}$ (approximately 3\%) in the PMMA. The use of $5 \%$ Chlorhexidine gluconateled to lower Tg (approximately $11 \%$ ) in the POM. The use of $2 \%$ sodium hypochlorite and Corega Tabs led to lower $\mathrm{Tg}$ (approximately 3-4\%) in the 
POM.

3. Corega Tabs do not affect the viscoelastic properties of POM and may be recommended for disinfecting prosthetics. $5 \% \quad$ Chlorhexidine gluconate and $2 \%$ sodium hypochlorite do not affect the viscoelastic properties of PMMA; 5\% Chlorhexidine gluconate and $2 \%$ sodium hypochlorite may therefore be usable as PMMA disinfectants.

\section{REFERENCES}

1. Turmer JW, Radford DR, Sherriff M. Flexural properties and surface finishing of acetal resin denture clasps. J Prosthodontics 1999;8:188-195.

2. Al-Akhali MA, El-Kerdawy MW, Ibraheim ZA, Abbas NA. Comparative study on the microbial adhesion to acetal resin and metallic removable partial denture. Ind J Dent 2012;3:1-4.

3. Polyzois G1, Niarchou A, Ntala P, Pantopoulos A, Frangou M. The effect of immersion cleansers on gloss, colour and sorption of acetal denture base material. Gerodontology 2013;30:150-156.

4. Arda T, Arikan A. An in vitro comparison of retentive force and deformation of acetal resin and cobalt-chromium clasps. J Prosthet Dent 2005;94:267-274.

5. Arikan A, Ozkan YK, Arda T, Akalın B. Effect of 180 days of water storage on the transverse strength of acetal resin denture base material. J Prosthodont 2010;19:47-51.

6. Negrutiu $M$, Sinescu $C$, Roman $M$, Pop D, Lakatos S. Thermo-plastic resins for flexible framework removable partial dentures. Timisoara Med J 2005;55:295-299.

7. Pavarina AC, Machado AL, Giampaolo ET, Vergani CE. Effect of chemical disinfectanats on the transverse strength of denture base acrylic resins. J Oral Rehabil 2003;30:1085-1089.

8. OrsiIA,AndradeVG.Effect of chemical disinfectants on the transverse strength of heat-polymerized acrylic resins submitted to mechanical and chemical polishing. J Prosthet Dent 2004;92:382-388.

9. Honorez.P, Catalan A, Angnes U, Grimonster J. The effect of three processing cycles on some physical and chemical properties of a heatcured acrylic resin. J Prosthet Dent 1989;61:510-517.

10. Chitchumnong $P$, Brooks SC, Stafford GD. Comparison of threeand four-point flexural strength testing of denture-base polymers. Dent Mater 1989;5:2-5.

11. Powell GL, Runsells RD, Saon BA, Whisenant BK. The presence and identification of organisms transmitted to dental laboraties. J Prosthet Dent 1990;64:235-237.

12. Pavaria AC, Pizzolitto AC, Machado AL, Vergani CE, Giampaolo ET. An infection control protocol: Effectiveness of immersion solutions to reduce the microbial growth on dental prostheses. J Oral Rehabil 2003;30:532-536.

13. Lin JJ, Cameron SM, Runyan DA, Craft DW. Disinfection of denture base acrylic resin. J Prosthet Dent 1999;81:202-206.

14. McCabe JF, Murray ID, Kelly PJ. The efficacy of denture cleansers. Eur J Prosthodont Res Dent 1995;3:203207.

15. Neppelenbroek KH, Pavarina AC, Vergani CE, Giampaolo ET. Hardness of heat-polymerized acrylic resins after disinfection and long-term water immersion. J Prosthet Dent 2005;93:171-176.

16. Gornitsky M, Paradis I, Landaverde G, Malo AM, Vlly AM. A clinical and 
microbiological evaluation of denture cleaners for geriatric patients in longterm care institutions. J Can Dent Assoc 2002;68:39-45.

17. Robinson RG, McCabe JF, Storer R. Denture bases: The effect of various treatments on acrylic, strength and structure. J Dent 1987;15:159-165.

18. Peracini A, Davi LR, Ribeiro NQ, Souza RF, Lovato CH, Paranhos HFO. Effect of denture cleaners on physical properties of heat-polimerized acrylic resin. J Prosthodont Res 2010;54:78-83.

19. Asad T, Watkinson AC, Hugget R. The effect of disinfection procedures on flexural properties of denture base acrylic resins. J Prosthet Dent 1992;68:191-195.

20. Shen C, Javid NS, Colaizzi F. The effect of glutaraldehyde base disinfectants on denture base resins. J Prosthet Dent 1989;61:583-589.

21. Pavarina AC, Vergani CE, Machado Al, Giampaola ET, Teraoka MT. The effect of disinfectant solutions on the hardness of acrylic resin denture teeth. J Oral Rehabil 2003;30:749752.

22. Chau VB, Saunders TR, Pimsler M, Elfring DR. In-depth disinfection of acrylic resins. J Prosthet Dent 1995;74:309-313.

23. Angelillo IF, Bianco A, Nobile CGA, Pavia M. Evaluation of the efficacy of glutaraldehyde and peroxygen for disinfection of dental instruments. Lett Appl Microbiol 1998;27:292296.

24. Ayaz EA, Turgut S, Korkmaz FM, Tamam E, Bağış B. Protez temizleme preparatlarının farklı yapidaki yapay dişlerin renk stabilitesine etkisi. Cumhuriyet Dent J 2014;17:32-41.

25. Arab J, Newton JP, Lloyd CH. The importance of water temparature in denture cleaning procedures. J Dent 1988;16:277-281.
26. Sultania $M$, Yadaw $S B$, Rai JSP, Srivastava D. Laminates bades on vinyl ester resin and glass fabric: A study on the thermal, mechanical and and morphological characteristics. Mater Sci and Eng A 2010;527:4560-4570.

27. Waters $M$, Jagger $R$, Williams $K$, Jerolimov V. Dynamic mechanical thermal analysis of denture soft lining materials. Biomaterials 1996;17:1627-1630.

28. Muhtaroğulları IF, Doğan A, Muhtaroğulları M, Usanmaz A. Thermal and dynamic mechanical properties of Microwave and heatcured poly (methyl methacrylate) used as dental base material. J Appl Polymer Sci 1999;74:2971-2978.

29. Murata H, Seo RS, Hamada $T$, Polyzois GL, Frangou MJ. Dynamic mechanical properties of hard, direct denture reline resins. J Prosthet Dent 2007;98:319-326.

30. Usanmaz A, Eser O, Doğan A. Thermal and mechanical properties of $\gamma$-ray cured poly (methyl methacrylate) used as dental base material. J Appl Polymer Sci 1999;81:1291-1296.

31. Caussé N, Cortes LQ, Dantras E, Tonon C, Chevalier M, Combes $\mathrm{H}$, Guigue P, Lacabanne C. New bonded assembly configuration for dynamic mechanical analysis of adhesives. Int J Adhes Adhes 2013;29 (in press).

32. Can G, Ozdemir T, Usanmaz A. Effect of thermocycling and treatment with monomer on mechanical properties of soft denture liner Molloplast B. Int $\mathrm{J}$ Adhes Adhes 2009;29:812-814.

33. Braden $\mathrm{M}$. The absorption of water by acrylic resins and other materials. J Prosthet Dent 1964;14:307-316.

34. Cucci AL, Vergani CE, Giampaolo ET, Afonso MC. Water sorption, solubility, and bond strength of two autopolymerizing acrlic resins an 
done heat-polymerizing acrylic resin. J Prosthet Dent 1998;80:434-438.

35. Vouvoudi EC, Sideridou ID. Dynamic mechanical properties of dental nanofilled light-cured resin composites: Effect of food-simulating liquids. J Mech Behav Biomed Mater 2012;10:87-96.

36. Hamanaka I, Iwamoto M, Lassila L, Vallittu P, Shimizu H, Takahashi Y. Influence of water sorption on mechanical properties of injectionmolded thermoplastic denture base resins. Acta Odontol Scand 2014;22:1-7.

37. Tolidis K, Papadogiannis $\mathrm{D}$, Gerasimou P. Dynamic and static mechanical analysis of resin luting cements. J The Mech Behav Biomed Mater 2012;6:1-8.

38. Ruyter I.E. and Svendsen S.A. Flexural properties of denture base polymers. J Prosthet Dent 1980;43:95-104.

39. Phoenix RD, Mansueto MA, Ackerman NA, Jones RE. Evaulation of mechanical and thermal properties of commonly used denture base resins. J Prosthodontics 2014;13:17-27.

40. Peutzfeldt A, Garcia-Godoy F, AsmussenE. Surfacehardness and wear of glass ionomers and compomers. Am J Dent 1997;10:15-17.
41. Pisani MX1, Macedo AP, Paranhos HdeF, Silva CH. Effect of experimental Ricinus communis solution for denture cleaning on the properties of acrylic resin teeth. Braz Dent J 2012;23:15-21.

42. Paranhos Hde F, Peracini A, Pisani MX, Oliveira Vde C, de Souza RF, Silva-Lovato CH. Color stability, surface roughness and flexural strength of an acrylic resin submitted to simulated overnight immersion in denture cleansers. Braz Dent J 2013;24:152-156.

43. Campanha NH, Pavarina AC, Jorge JH, Vergani CE, Machado AL, Giampaolo ET. The effect of long-term disinfection procedures on hardness properties of resin denture teeth. Gerodontology 2012;29:571-576.

44. Pisani MX1, da Silva $\mathrm{CH}$, Paranhos HF, Souza RF, Macedo AP. Evaluation of experimental cleanser solution of Ricinus communis: Effect on soft denture liner properties. Gerodontology 2012;29:e179-185.

45. Alaa Al-Haddad, Vahid Roudsari R, Satterthwaite JD. Fracture toughness of heat cured denture base acrylic resin modified with Chlorhexidine and Fluconazole as bioactive compounds. J Dent 2014:42:180-184. 